\title{
Gender Differences in Attitudes and Achievement in Mathematics among Ghanaian JHS Students
}

\author{
Derrick Anokye-Poku ${ }^{1, *} \&$ Ernest Ampadu ${ }^{1}$ \\ ${ }^{1}$ Department of Teacher Education, University of Ghana, Ghana \\ *Corresponding author: Department of Teacher Education, University of Ghana, Ghana. \\ E-mail: danokyepoku@yahoo.com
}

Received: June 2, 2020 Accepted: July 17, 2020 Published: September 17, 2020

doi:10.5296/ije.v12i3.17136 URL: https://doi.org/10.5296/ije.v12i3.17136

\begin{abstract}
Students' learning and performance in mathematics is affected by several factors, including students' attitude. This paper aims to understand the gender differences in attitude toward mathematics and mathematics achievement. A descriptive survey design was used, and the participants consisted of 360 Junior High School students. Two instruments, semi-structured questionnaire and students test scores were used. The results revealed that, in general, both female and male students held positive attitudes towards mathematics, and there was no significant difference in attitudes between genders toward mathematics. However, the results established that there was a significant difference in achievement. It was recommended that to achieve sustainable development goal 4, teachers, parents, and educational authorities should develop creative and innovative ways of helping students, especially female students to build self-confidence in the learning of mathematics.
\end{abstract}

Keywords: attitudes, gender, mathematics, achievement, Junior High School, sustainable development goals, learning 


\section{Introduction}

Mathematics continues to be the fulcrum on which life centres on. It is a globally accepted phenomenon that life without mathematics would practically not be possible because mathematics permeates into all studies. Simply put; one cannot buy, sell, communicate, travel, eat, wear and even sleep without numerical (Mathematical) concept being put in use. This world, for some time, now has put so much emphasis on science and technology. Kavkler, Magajna and Babuder (2014) have postulated that mathematics in this technological era become an essential tool for developing rational human personality. That is, mathematical knowledge develops in people critical thinking for most especially life and career decisions.

The importance of mathematics has contributed significantly in mathematics classified as a core subject for both at the basic and second cycle levels of education in Ghana. It is a requirement for admission into secondary school and prestigious courses at the tertiary (University, Polytechnic, Colleges of Education, etc.) level (Anamuah-Mensah, Asabere-Ameyaw, and Dennis, 2005) of education in Ghana. Contrary to this, the performance of students in mathematics has never escaped past and current researchers. Mireku (2012) has reported the extend at which National large scale assessments like NEA, EGRA and EGMA and BECE and WASSCE which are national examinations as well as international examinations like TIMSS have unearthed the poor performance of Ghanaian students in mathematics in recent times. For example, the low mean score of 276 that placed Ghana $45^{\text {th }}$ out of $46^{\text {th }}$ position in the TIMSS 2003 (Anamuah-Mensah, Mereku and Asabere-Ameyaw, 2004), the $47^{\text {th }}$ out of 48 countries in 2007 with the lowest mean scale scores of 130 and 430 as compared to 500 and 800 (Anamuah-Mensah, Mereku \& Ghartey-Ampiah, 2008) and $42^{\text {nd }}$ out of the 42 countries in 2011 are all clear attestation of the poor performance of Ghanaian students. In the discourse of these poor mathematics performance shown by students, the attitudes of students have been identified to be very crucial (Farooq \& Shah, 2008; Blair, 1975) and therefore the need to kindle a change in students attitude towards mathematics (Chief Examiner's Report, 2011).

\subsection{Statement of the Problem}

It is worth noting that gender difference in attitudes and achievement in mathematics continues to attract major attention in research. Battey (2013) opines how gender has continued to be a dividing status for researchers, and as a result, its effect on the studying of mathematics. Similarly, research by Mata, Monteiro and Piexoto (2012) also illuminates the recurrent nature of attitude towards learning in respect to gender across the length and breadth of academic studies in general but most notably in the studies of mathematics. There have been varying results as to who performs better than the other. Whereas some studies put boys at performing better than girls (e.g. Preckel, Goetz, Pekrun, \& Kleine, 2012; Skaalvik \& Skaalvik, 2004), others put girls at performing better than boys (e.g., Stevens, Wang, Olivarez, $\&$ Hamman, 2007). On the other hand, some studies have shown no difference between boys and girls (Mohamed \& Waheed, 2011; Lindberg, Hyde, Petersen, \& Linn, 2013) at all. The achievement of Sustainable Development Goal 4 therefore is a wake up call in our quest for providing equal opportunities for all our students irrespective of gender, class, race and ability. 
It is upon this bedrock that the researchers believe that improving students performance in mathematics in Ghana and the provision of opportunities to learn mathematics for all students requires a critical look at the gender differences in students attitudes and achievement in mathematics. Despite the numerous literature in examining the aforementioned issues (e.g. Asante, 2010; Mensah, Okyere, \& Kuranchie, 2013) the scarcity of research into the gender difference in attitudes of JHS students in the mathematics of schools mainly in the Asunafo South District of the Ahafo Region in Ghana has motivated the authors to use this study to add to the existing body of knowledge.

\subsection{Purpose of the Study and Research Questions}

The study looks at the attitudes of JHS students in mathematics in the Asunafo South District of Ghana. Also, it seeks to find out among boys and girls those who achieve better so far as performance in mathematics is a concern. The following research questions, therefore, guide the present study;

- Is there any relationship between gender and students attitudes toward mathematics?

- Is there any relationship between gender and achievement in mathematics among JHS students?

\subsection{Significance of the Study}

The results from this study will help teachers to adopt appropriate and varying methods to develop in students (both boys and girls) same or similar interest and performance in mathematics. It will also help the Ministry of education and its affiliates in policy initiatives to promote better attitude and achievement in mathematics among boys and girls. The study will again aid in further research by proving a framework for understanding the reasons behind the varying changes in attitude towards mathematics and gender.

\subsection{Theoretical Framework and Empirical Studies}

\subsubsection{Gender Differences and Attitudes in Mathematics}

Male and female students experience their worlds in diverse manners as a result of the constructs of gender roles (Paechter, 1998). Review of literature on gender and mathematics show that Mathematics is made to favour male learning patterns. However, what is more interesting, as argued by Mutemri and Mygweni (2005) is that the mere perception that mathematics is male-centred results in low participation from females. The different learning objectives of males and females leave females at a significant disadvantage in the competitive environment. Females tend to be drawn towards mathematical concepts that allowed them to imagine and reason at their own pace while developing possible solutions. Males, on the other hand, tend to see precision and speed as indicators of their understanding of mathematics.

Attitude and perception play a crucial role in the learning of mathematics. Early research shows that males did significantly better than females at the Junior High and High School levels, as there were apparent differences in attitudes towards mathematics (Fennema \& 
Sherman, 1977). Similarly, Hyde, Fennema, and Eamon (1990) in a related study through a meta-analysis reveals that males tend to do better on mathematics tests that involve problem-solving. Chouinard, Vezeau, Bouffard, and Jenkins (1999) found that many of the differences in attitudes were stronger in the early ages and tended to diminish in later ages. They, however, added that societal constructs and teachers actions and inactions could encourage either a positive or negative attitude. Marger (2008) added that the societal constructs where males are encouraged to pursue lucrative careers which are usually STEM-based simply because they are potential breadwinners of the nuclear family might also explain the differences in gender and attitudes towards mathematics.

Mohamed and Waheed (2011) examined students attitudes and how these influence their development and identified three groups of factors: students related factors (e.g., mathematical achievement, anxiety, self-efficacy and self-concept, motivation, and experiences at school); school, teacher, and teaching-related factors (e.g., teaching materials, classroom management, teacher knowledge, attitudes towards maths, guidance, beliefs), and home environment and social factors (e.g., educational background, parental expectations). Hyde et al. (1990) in their research prove that gender effects, which increase among older students, led to females holding more negative attitudes. Asante (2010) also states that, when compared with boys, girls lack confidence, had debilitating causal attribution patterns, perceived mathematics as a male domain, and were anxious about mathematics. This posits that males generally carried more positive attitudes than females in the area of Mathematics and other science-related subjects.

\subsubsection{Relationship between Attitudes and Achievement in Mathematics}

Examining the relationship between attitudes and achievement has received much attention over the last three decades. Most studies have established a positive correlation between students attitudes and achievements in Mathematics. Michelli (2013) in examining the aforementioned issue among fifth grade students established that there is a direct relationship between attitude and performance in mathematics. The findings also established that sex played a key role in determining the relationship between attitude and performance. In addition, several types of traits were examined, including extraversion, awareness, self-control, and the intellectual ability to determine their impact on performance. The findings are therefore a wake up call on especially educators on how they ought to be in knowing of students' attitude and the need to improve on them to influence their performances (i.e. academic achievement) positively. A study by Ramírez (2005) also established that the importance of students studying mathematics, expectations for continuing education and confidence in the causes of their math scores were important predictors of performance. He therefore added that despite the direct relationship between attitudes and achievement in mathematics, other contributing factors as mentioned above cannot be underestimated in our quest for helping students develop positive attitudes toward Mathematics.

According to Mensah, Okyere, and Kuranchie (2013) attitudes towards mathematics implies a liking or disliking of mathematics, a tendency to engage in or avoid mathematical activities, 
a belief that one is good or bad at mathematics, and a belief that mathematics is useful or useless". Attitudes toward mathematics have been found to be generally negative, especially within domains such as sub-Saharan Africa and more especially Ghana. The effect of such negative attitudes (as well as other factors) on school achievement, has been consistently evident in the poor mathematics performances of Ghanaian students in national examinations like the BECE and WASSCE (Mensah et al. 2013). It is therefore not surprising to see significant efforts being extended by governments and other key stakeholders across the globe, to ensure adequate training of many students STEM (science, technology, engineering and mathematics). Many research works have thus explored the factors that inform such poor performances in mathematics among Ghanaian students, intending to proffer relevant solutions to stakeholders (Mereku \& Anamuah-Mensah, 2005; Butakor, Ampadu \& Cole, 2017; Arhin, 2015).

Mensah et al. (2013), explored the interaction effect of teachers attitude towards maths on the attitudes of their students towards the subject, and how the attitudes of such students predict their performances in Mathematics. They used a cross-sectional survey design, the study sampled $2^{\text {nd }}$ and $3^{\text {rd }}$-year students from selected Senior High schools in Ghana, with a further sample of teachers who had taught such students for at least a year. Interestingly, the researchers found a moderately positive and statistically significant correlation between teachers' attitudes towards mathematics and the attitudes of their students. Further to this critical finding, it was also revealed that students with positive attitudes towards mathematics tended to perform better in the subject academically, than those with negative attitudes. This could thus be attributed to the fact that students with positive mathematics attitudes may engage more in mathematics-related activities (e.g. studying) than the other comparative group (Asante, 2012; Mata, Monteiro \& Peixoto, 2012).

One intriguing result from the study above, however, was the weak correlation established between teachers' mathematics attitudes and students' performance in the subject. In effect, although there was a strong relationship between teachers' attitudes and students' attitudes, a direct effect of the positive/negative attitudes of teachers on students' mathematics performance could not be established. Thus, it can be inferred that the attitudes of teachers can influence students' performance levels, only if such attitudes are reflected in the students as well.

Consistent with the findings of Mensah et al. (2013) another essential study conducted using 8,220 students from Japan and 10,070 students from the US (House, 2010), established a strong positive correlation between self-belief in mathematics and achievement on tests. From this study, students who hold positive self-belief systems about mathematics (i.e. mathematics is easy, interesting etc.) recorded higher scores on mathematics as compared to students with negative self-belief systems (i.e. mathematics is boring, complex, success is only by lack etc.). This particular finding is consistent with the results of another study which highlighted a significant positive relationship between attitudes and achievement in mathematics problem solving as well as self-efficacy and achievement (Nicolaidou \& Philippou, 2004). House (2010) study further revealed that students with positive belief systems (attitudes) tend to also believe in hard work and constant practice as critical measures 
for attaining higher achievements in mathematics, and thus engaged in such actions regularly. All other things being equal, this logically explains their reported high scores in mathematics as compared to other negatively oriented students (House, 2010; Schenkel, 2009).

\subsubsection{Causes of Gender Differences in Attitudes towards Mathematics}

Mathematics as a subject of study in schools continues to divide opinion along the lines of gender differences and students performances thereof. Many studies have therefore sort to understand the gender dynamics when it comes to students attitudes towards mathematics as a subject, and the causes underlying these differences. Frome and Eccles, 1998 (cited in Morrissey et al., 2019), established a significant gender disparity in the attitudes of students and the pursuit of maths-related careers. Interestingly, a less considerable variation was, however, seen in terms of the effect of such attitudinal differences on performance levels in mathematics.

In a study conducted by Mohammed and Abdul-Razak (2018), the researchers found a rather opposing result to the widely held perception that females have an inherent phobia to mathematics as opposed to their male counterparts, and thus report higher levels of dislike for the subject. The study which aimed at exploring the effects of gender and school type on attitudes of students toward mathematics sampled 180 students from 3 different secondary schools in Malaysia. Principally, the study found near non-existence of the perceived positive dominance (in terms of attitude) of males toward mathematics relative to females. Key among its findings is the role school-types could play in altering the gender-related differences in attitudes towards mathematics. Female students from mixed-gender schools appeared to report lower levels of mathematics competence/self-belief than those in single-sex schools, as the latter actively perceive that mathematics is useful and do not think that mathematics is a male domain (Mohammed \& Abdul-Razak, 2018). Although the study generally concluded that gender might not be a good precursor to attitudes towards mathematics, it revealed that school type could be an important factor that could moderate the gender-biased attitudes of students towards mathematics.

Elsewhere, Morrison et al. (2019), also identified age as a possible mediating or causative factor in the math-gender differences that may be observed among students. The study focused primarily on the implicit math-gender stereotypes that exist in both adults and adolescents in Canada, through implicit and explicit math-language gender stereotype tests. Conclusions from the study revealed that adults (sampled through voluntary subject pools) reported higher endorsements of math-gender stereotypes, compared to the adolescents involved in the study (Junior High School students). Thus, adults perceived mathematics to be a more gendered subject (favouring males) as opposed to the perceptions of adolescents (who reported less significant math-gender stereotypes). In effect, the age groups of individuals or students play a crucial role in mediating or determining the gender-based differences which may be expressed towards mathematics as a subject. 


\section{Methods}

The descriptive survey design was adopted for the study. The study had a target population of all Junior Secondary School (JHS), both public and private in the Asunafo South District of Ghana. The Educational directorate had eight circuits, and the researcher adopted them to serve as strata for the study. A purposive sampling technique was, however, use to select 3 schools each from strata to make a total of 24 schools from the accessible population of 73 schools in the Asunafo South District. The total participants ware 360 comprising of 216 males and 144 females. In all, 15 students made up of 3 males each and 2 females each from JHS1-3 were randomly chosen from the 24 schools for the questionnaire.

A semi-structured questionnaire and students' end-of-term exams scores were the instruments for the study. The semi-structured questionnaire was in two parts. The first part collected demographic information from the students and the second part had 9 questions that enquired from students their personal view and relevance of mathematics. All the 9 items were set on a four-point Likert scale ranging from strongly Agree (SA), Agree (A), Disagree (D) and Strongly Disagree (SD). In order to ensure the validity and reliability of the instrument, it was piloted with 15 students from three schools within the district. Cronbach's alpha of 0.79 in reliability testing was enough reason to attest to the reliability of the questionnaire. The data collected were entered and analysed with the help of the Statistical Package for Social Sciences (SPSS 16.0). Descriptive statistics (percentages, mean, and standard deviation) and inferential statistics (t-test and correlation) were used for the analysis.

\section{Results}

\subsection{RQ1: Relationship between Gender and Students Attitudes toward Mathematics}

To answer this question, an Independent T-test of gender and student attitudes toward mathematics was used. In all students response to nine items measuring their attitudes toward mathematics was used to measure the relationship between gender and attitudes. The result is depicted in Table 1.

Table 1. Relationship between Gender and Students Attitudes toward Mathematics

\begin{tabular}{lllllll}
\hline Gender & $\mathrm{N}$ & Mean & $\mathrm{SD}$ & $\mathrm{df}$ & $\mathrm{t}$ & $\mathrm{p}$ \\
\hline Males & 216 & 3.02 & 0.964 & 358 & 0.33 & 0.741 \\
Females & 144 & 3.01 & 0.962 & & & \\
\hline
\end{tabular}

$\mathrm{P}<0.05$

From the above, male students $(\mathrm{M}=3.02, \mathrm{SD}=0.964)$ and female students $(\mathrm{M}=3.01, \mathrm{SD}=$ $0.962),\left[\mathrm{t}{ }_{(108)}=0.33, \mathrm{p}=0.741\right]$ shows that there is no significant difference in attitudes between genders toward mathematics. Although male student ascribed more positively to the 
statements as compared to their female counterparts, there was no significant difference between their attitudes. However, it is interesting to note that analysis of the descriptive statistics shows that the female students ascribed more positively to statements concerning the relevance of mathematics and their perseverance to getting a mathematics task done. For example, more females ascribed positively to questions asking about how they see the relevance of the mathematics they are learning, how the concepts learnt will help them in solving real-life problems. Also, on the issue of how they are eager to continue working hard on their mathematics activities and assignments even when it gets hard, most females ascribed positively to this statement. This positive attitudes toward can be assumed to be an asset in our quest for helping students, especially females, to develop a positive attitude toward mathematics and science-related courses. Hence the use of creative and more innovative approaches can help and support students develop a positive attitude toward mathematics. Helping students understand the utilitarian motive behind the mathematical concepts that they are learning can also help in our quest for helping students develop positive attitudes. This is because the majority of the students indicated that they know the importance of the mathematics they are learning in solving real-life problems.

\subsection{RQ2: Relationship between Gender and Achievement in Mathematics}

After understanding students attitudes toward mathematics, it was essential to examine if there is any relationship between gender and students achievement. To achieve this, an independent T-test was used to test for the differences in Mean and Standard Deviations between gender and mathematics achievement. To examine the relationship between attitude toward mathematics and achievement students exams scores were correlated with their attitudes, and for easy analysis, students who scored 50\% and above were classified as above average. Those who scored below 50\% were classified as below average. The result is shown in Table 2.

Table 2. Relationship between Gender and Mathematics Achievement

\begin{tabular}{llllllll}
\hline & & $\mathrm{N}$ & Mean & $\mathrm{SD}$ & $\mathrm{Df}$ & $\mathrm{T}$ & $\mathrm{P}$ \\
\hline \multirow{2}{*}{ Male } & Above Average & 206 & 66.01 & & & & \\
& $\begin{array}{l}\text { Below Average } \\
\text { Female }\end{array}$ & 10 & & 7.59 & & \multirow{2}{*}{7.2} & 0.001 \\
& $\begin{array}{l}\text { Above Average } \\
\text { Below Average }\end{array}$ & 135 & 60.88 & & 358 & & \\
\hline
\end{tabular}

$\mathrm{P}<0.05$

In Table 1 it was established that there is no difference in attitudes between genders toward mathematics; however, from Table 2, it is clear that male students performed better than their female counterparts. Male students $(M=66.01, S D=7.59)$ and female students $(M=60.88$, $\mathrm{SD}=4.79),[\mathrm{t}=7.2, \mathrm{p}=0.001]$ shows that there is a significant difference in achievement among genders. However, it can be argued that despite male students performing better than the female counterparts, a standard deviation of 7.59 and 4.79 for males and females 
respectively suggest that the males' scores were widely dispersed from the mean as compared to that of the females. It is, therefore, possible that the males' results were not fairly distributed as compared to that of females. It is also worth noting that the percentage of male $(4.6 \%)$ students who scored below average was just a two-percentage score different from that of their female $(6.6 \%)$ counterparts.

\section{Discussion and Implications}

The paper sought to investigate the relationship between gender and students' attitudes towards the learning of mathematics and if there is any difference between gender and achievement in mathematics. The study found that the majority of the respondents showed positive attitudes toward mathematics and ascribed that the learning of mathematics has utilitarian motives in their quest for furthering their education or using mathematics in solving real-life problems. The results also established that there is no significant difference in attitudes between genders toward mathematics. Similar to the findings of Mohammed and Abdul-Razak (2018) the results proved that despite the numerous studies that have suggested that females have an inherent phobia to mathematics as opposed to their male counterparts, the findings indicate that there is no significant difference.

The findings from Mutemri and Mygweni (2005) established that the mere perception that mathematics is male-centred could result in low participation and achievement among females. Marger (2008) also found that the societal constructs where males are encouraged to pursue lucrative careers which are usually STEM-based might also explain the differences in gender and attitudes and achievements in mathematics. The findings from the study established that despite the majority of females showing a positive attitude toward mathematics, there exists a significant difference in achievements between males and females. Male students performed better with an average score of $66.01 \%$ as compared to their female $(60.88 \%)$ counterparts. However, it was interesting to note that the male students had a higher standard deviation suggesting that their results were widely dispersed from the mean as compared to the female counterparts. This may indicate that despite the variations in the performances, not all the male students may have an average score of $66.01 \%$.

Similar to the findings of Mensah and Kuranchie (2013) and the results from the study found a positive relationship between students' attitudes and achievement in mathematics. From the descriptive statistics, only $6.6 \%$ and $4.6 \%$ of the females and males respectively had a score below the average score of $50 \%$. The underlining principles of every current school curriculum, including that of Junior High School curriculum is working towards achieving Sustainable Development Goal 4. SDG 4 is aimed at ensuring inclusive and equitable quality education and promote lifelong learning opportunities for all learners. From the results from this study, it is clear that to achieve this the issue of gender differences in attitudes and academic achievement in mathematics is critical. It is therefore essential for teacher, parents and other stakeholders in the education sector come together in providing equal opportunities for all students. We recommend that parents and teachers help students, especially female students, to develop self-confidence among themselves. Also, there is a need for creative and 
innovative ways of teaching mathematics so that student will develop a conceptual understanding of the concepts learnt.

\section{References}

Anamuah-Mensah, J., Asabere-Ameyaw, A., \& Dennis, S. (2005). Bridging the gap, Linking school and the world of work in Ghana. Journal of Career and Technical Education, 23(1), 13. https://doi.org/10.21061/jcte.v23i1.449

Anamuah-Mensah, J., Mereku, D. K., \& Asabere-Ameyaw, A. (2004). Ghanaian Junior Secondary School Students' Achievement in Mathematics and Science: Results from Ghana's participation in the 2003 Trends in International Mathematics and Science Study. Accra: Ministry of Education Youth and Sports.

Anamuah-Mensah, J., Mereku, D. K., \& Ghartey-Ampiah, J. (2008). TIMSS 2007 Ghana Report: Findings from IEA's Trends in International Mathematics and Science Study at the Eighth Grade. Accra: Ministry of Education.

Asante, K. O. (2010). Sex differences in mathematics performance among senior high students in Ghana. Gender and Behaviour, 8(2), 3279-3289. https://doi.org/10.4314/gab.v8i2.61947

Battey, D. (2013). Good mathematics teaching for students of color and those in poverty: the importance of relational interactions within instruction. Educational Studies in Mathematics, 82(1), 125-144. https://doi.org/10.1007/s10649-012-9412-z

Blair, G. M. (1975). Educational Psychology, measurement and evaluation (4th ed.). New York: McGrew Hill.

Chouinard, R., Vezeau, C., Bouffard, T., \& Jenkins, B. (1999). Gender differences in the development of mathematics attitudes. Journal of Research \& Development in Education, 32(3), 184-192.

Farooq, M. S., \& Shah, S. Z. (2008). Students' attitude towards mathematics. Pakistan Economic and Social Review, 46(1), 75-83.

Fennema, E., \& Sherman, J. (1977). Sex-related differences in mathematics achievement, spatial visualisation and affective factors. American Educational Research Journal, 14(1), 51-71. https://doi.org/10.3102/00028312014001051

House, J. D. (2010). Mathematics beliefs and achievement of elementary school students in Japan and the United States: Results from the third international mathematics and science study. The Journal of Genetic Psychology, 167(1), 31-45. https://doi.org/10.3200/GNTP.167.1.31-45

Hyde, J. S., Fennema, E., \& Lamon, S. J. (1990). Gender differences in mathematics performance: A meta-analysis. Psychological Bulletin, 107, 139-155. https://doi.org/10.1037/0033-2909.107.2.139 
Kavkler, M., Magajna, L., \& Košak Babuder, M. (2014). Key factors for successful solving of mathematical word problems in fifth-grade learners. Health Psychology Report, 2(1), 27-38. https://doi.org/10.5114/hpr.2014.42787

Lindberg, S. M., Hyde, J. S., Petersen, J. L., \& Linn, M. C. (2013). New trends in gender and mathematics performance. A meta-analysis. Psychological Bulletin, 136(6), 1123-1135. https://doi.org/10.1037/a0021276

Marger, M. (2013). Social inequality: Patterns and processes. New York, NY: McGraw-Hill Higher Education.

Mata, M. L., Monteiro, V., \& Piexoto, F. (2012). Attitude towards mathematics: Effects of individual, motivational, and social support factors. Child Development Research. https://doi.org/10.1155/2012/876028

Mensah, J. K., Okyere, M., \& Kuranchie, A. (2013). Student attitude towards Mathematics and performance: Does the teacher attitude matter? Journal of Education and Practice, 4(3), 132-139.

Mereku, D. K. (2012). Quality Education, Challenges of Less Endowed Schools; the role of the students. A paper presented at the 2nd Speech and Prize Given Day Celebration of the Apeguso SHS, E.R.p1.

Michelli, M., P. (2013). The relationship between attitudes and achievement in Mathematics among fifth grade students. Honors Theses, 126. Retrieved 12 April, 2019 from https://aquila.usm.edu/honors_theses/126

Mohamed, A. N., \& Razak, F. A. (2018, November). Effects of gender and school type on attitudes towards mathematics. Journal of Physics: Conference Series, 1132(1), 12-38. https://doi.org/10.1088/1742-6596/1132/1/012038

Mohamed, L., \& Waheed, H. (2011). Secondary students' attitude towards mathematics in a selected school of Maldives. International Journal of humanities and social science, 1(15), 277-281.

Morrisey, K., Hallet, D., Bakhtiar, A., \& Fitzpatrick C. (2019). Implicit math-gender stereotype present in adults but not in $8^{\text {th }}$ grade. Journal of Adolescence, 74(2019), 173-182. https://doi.org/10.1016/j.adolescence.2019.06.003

Mutemeri, J., \& Mugweni, R. (2005). The extent to which mathematics instructional practices in early childhood education in Zimbabwe relates to or makes use of children's experiences. African Journal of Research in Mathematics, Science and Technology Education, 9(1), 49-54. https://doi.org/10.1080/10288457.2005.10740576

Nicolaidou, M., \& Philipou, G. (2004). Attitudes towards Mathematics, Self-efficacy and Achievement in Problem Solving. European Research in Mathematic Education III, 2.

Preckel, F., Goetz, T., Pekrun, R., \& Kleine, M. (2008). Gender differences in gifted and average-ability students: Comparing girls' and boys' achievement, self-concept, interest, 
and motivation in mathematics. Gifted Child Quarterly, 52(2), 146-159. https://doi.org/10.1177/0016986208315834

Ramírez, M. J. (2005). Attitudes toward mathematics and academic performance among Chilean 8th graders. Estudios Pedagógicos, 31(1), 97-112. https://doi.org/10.4067/S0718-07052005000100006

Skaalvik, S., \& Skaalvik, E. (2004). Gender differences in math and verbal self-concept, performance expectations and motivation. Sex roles, 50(3-4), 241-251. https://doi.org/10.1023/B:SERS.0000015555.40976.e6

Stevens, T., Wang, K., Olivarez Jr. A., \& Hamman, D. (2007). Use of self-perspectives and their sources to predict the mathematics enrollment intentions of girls and boys. Sex Roles, 56, 351-363. https://doi.org/10.1007/s11199-006-9180-2

\section{Copyright Disclaimer}

Copyright for this article is retained by the author(s), with first publication rights granted to the journal.

This is an open-access article distributed under the terms and conditions of the Creative Commons Attribution license (http://creativecommons.org/licenses/by/3.0/). 